\title{
Desorption of water cluster ions from the surface of solid rare gases
}

\author{
T. Tachibana, T. Miura, and I. Arakawa \\ Department of Physics, Gakushuin University, Mejiro, Toshima, \\ Tokyo 171-8588, Japan \\ E-mail: ich.arakawa@gakushuin.ac.jp
}

Received August 1, 2006

\begin{abstract}
Electron or photon irradiation on $\mathrm{H}_{2} \mathrm{O}$ adsorbed on the surface of rare gas solids induces the desorption of protonated water clusters, $\left(\mathrm{H}_{2} \mathrm{O}\right)_{n} \mathrm{H}^{+}$. The yield and the size $n$ distribution of cluster ions depend on the coverage, the deposition temperature of water and the thickness of a rare gas film. These results indicate that the $\left(\mathrm{H}_{2} \mathrm{O}\right)_{n} \mathrm{H}^{+}$ions are originated from the isolated water cluster and most important factor determining the size $n$ distribution of desorbed $\left(\mathrm{H}_{2} \mathrm{O}\right)_{n} \mathrm{H}^{+}$is the sizes of water islands on rare gas solid. The measurement of kinetic energy distributions indicated that the desorbing energy of clusters depend on the rare gas species of the substrates and the cluster size. It is suggested that the $\left(\mathrm{H}_{2} \mathrm{O}\right)_{n} \mathrm{H}^{+}$desorption is due to Coulomb repulsion between the ionic water cluster and the rare gas ion.
\end{abstract}

PACS: 36.40.-c

Keywords: desorption induced by electronic transitions, photon stimulated desorption, electron stimulated desorption, water, rare gas.

\section{Introduction}

The investigation of electronic excitation processes on an ice particle and the following chemical reactions is one of the most important subjects in the fields of environmental $[1,2]$ and planetary sciences $[3,4]$. In order to reveal the dynamics of electronic excited state of water molecules, the mechanism of desorption induced by electronic transitions (DIET) of cations [5-11], anions [12-15] and neutrals [16,17] from condensed or adsorbed $\mathrm{H}_{2} \mathrm{O}$ has been investigated by several groups.

Seiger and his coworkers [7] found desorption thresholds for electron-stimulated desorption (ESD) of $\mathrm{D}^{+}$from $\mathrm{D}_{2} \mathrm{O}$ ice near 22 and $40 \mathrm{eV}$. The primary electronic excitations which lead to this desorption have been assigned to several two-hole one-electron and two-hole two-electron configurations, whose states are dissociative, and the kinetic energy of the proton is likely to be generated by the Coulomb repulsion of the hole pair in a water molecule. Although ESD of ice multilayer leads to the $\mathrm{H}^{+}$desorption primarily, other heavy ions such as protonated water clusters, $\left(\mathrm{H}_{2} \mathrm{O}\right)_{n} \mathrm{H}^{+}(n=1-8)$, are also desorbed
$[6,8,9]$. Orlando and his coworkers found a threshold energy for the $\mathrm{H}_{3} \mathrm{O}^{+}$desorption near $22 \mathrm{eV}$ and for the $\left(\mathrm{H}_{2} \mathrm{O}\right)_{n} \mathrm{H}^{+}(n=2-8)$ near $70 \mathrm{eV}$. The yield of each cluster ions dramatically increased above the $70 \mathrm{eV}$ threshold [9]. The $\mathrm{H}_{3} \mathrm{O}^{+}\left(\mathrm{D}_{3} \mathrm{O}^{+}\right)$desorption was also confirmed in a photon stimulated desorption (PSD) study on water adsorbed on graphite using $41 \mathrm{eV}$ photons at $80 \mathrm{~K} \mathrm{[10].} \mathrm{It} \mathrm{was} \mathrm{suggested} \mathrm{that} \mathrm{the} \mathrm{produc-}$ tion and the desorption of hydronium ion in the low excitation energy range are due to ion-molecule reaction between energetic photo-dissociatived $\mathrm{H}^{+}\left(\mathrm{D}^{+}\right)$ and $\mathrm{H}_{2} \mathrm{O}\left(\mathrm{D}_{2} \mathrm{O}\right)$ molecule at the surface. The $70 \mathrm{eV}$ threshold for the cluster ions appears to be possible to create two holes in the $2 a^{-1}$ level on a water monomer or on two neighboring water molecules [8]. The average kinetic energy of desorbed clusters $(n=1-3)$ using $250 \mathrm{eV}$ electron was estimated to be in the range $(5 \pm 1) \mathrm{eV}$, which is nearly equal to the point-charge Coulomb potential energy for nearest neighbors $\mathrm{O}-\mathrm{O}$ distance in ice $(\sim 3 \AA)$ [9]. It has been interpreted that the desorption of $\left(\mathrm{H}_{2} \mathrm{O}\right)_{n} \mathrm{H}^{+}$caused by an intermolecular Coulomb repulsion on two adjacent ionic water molecules in the lattice. 
Electron or photon irradiation on $\mathrm{H}_{2} \mathrm{O}$ adsorbed on the surface of rare gas solids leads to the $\left(\mathrm{H}_{2} \mathrm{O}\right)_{n} \mathrm{H}^{+}$ desorption $[11,18,19]$, which is significantly enhanced at a submonolayer water coverage regime. The kinetic energy distribution of ESD cluster ions from the Ar substrate was measured by Souda [11]. The result indicated that the clusters have a mean kinetic energy of $\sim 1.8 \mathrm{eV}$. This value is lower than the energy of the clusters desorbed from a condensed ice. He has interpreted that the $\left(\mathrm{H}_{2} \mathrm{O}\right)_{n} \mathrm{H}^{+}$desorption is due to a Coulomb explosion between localized valence holes within a cluster and that the size distribution of desorbed $\left(\mathrm{H}_{2} \mathrm{O}\right)_{n} \mathrm{H}^{+}$relates to the hole-hole distances in a cluster. In our previous PSD experiments, the $\left(\mathrm{H}_{2} \mathrm{O}\right)_{n} \mathrm{H}^{+}$ desorption yields from water physisorbed on the rare gas solids ( $\mathrm{Ne}, \mathrm{Ar}, \mathrm{Kr}$, and $\mathrm{Xe}$ ) were measured as a function of the incident photon energy [19]. The $\left(\mathrm{H}_{2} \mathrm{O}\right)_{n} \mathrm{H}^{+}$yields were enhanced by multiple-excitation or -ionization of rare gas substrates. We suggested that the $\left(\mathrm{H}_{2} \mathrm{O}\right)_{n} \mathrm{H}^{+}$desorption is due to Coulomb repulsion between the rare gas ion and the protonated water cluster, which are produced by charge transfer between the multiply charged rare gas ion and the ground state $\mathrm{H}_{2} \mathrm{O}$ cluster. Although some of studies have discussed the $\left(\mathrm{H}_{2} \mathrm{O}\right)_{n} \mathrm{H}^{+}$desorption mechanism, little attention has been given to the examination of the sample temperature and thickness dependence of $\left(\mathrm{H}_{2} \mathrm{O}\right)_{n} \mathrm{H}^{+}$yield.

In this paper, we present the investigations of the distribution of cluster size $n$ and the desorption yield of $\left(\mathrm{H}_{2} \mathrm{O}\right)_{n} \mathrm{H}^{+}$, which depend on the coverage, the deposition temperature of water and the thickness of a rare gas film. The kinetic energy distribution of $\left(\mathrm{H}_{2} \mathrm{O}\right)_{n} \mathrm{H}^{+}$is also measured. It is found that the kinetic energy of the cluster ions depend on both the size of desorbed cluster ions and the rare gas species of the substrates.

\section{Experimental}

ESD and PSD experiments have been carried out in two independent UHV systems. The mass spectrum of desorbed ions was measured by a time-of-flight (TOF) technique. The water molecules were deposited on the solid rare gas or were adsorbed directly on a bare copper substrate. The thickness of a condensed rare gas film was calculated from the exposure assuming that the condensation coefficient was unity. The water, which was purified by multiple freeze-pump-thaw cycles, was effused from a small orifice directed toward the sample substrate. The coverage of water was estimated from the flow rate of water vapor with the cosine rule at the exit orifice.

A laser plasma vacuum ultraviolet light source (LPLS) has been developed as an excitation source for
PSD study. A Q-switched Nd-YAG laser beam $(1024 \mathrm{~nm})$ was focused on a rotatable cylindrical Ta target to produce metal plasma. The laser pulses were repeated at a frequency of $50 \mathrm{~Hz}$ with a pulse width of $\sim 10 \mathrm{~ns}$, and a typical laser energy was $550 \mathrm{~mJ} /$ pulse. The light emitted from the plasma was monochromatized with a toroidal grating and an exit slit and was introduced into a PSD experimental chamber. Three toroidal gratings covered the wavelength range from 4 to $108 \mathrm{~nm}$. The desorption signal was normalized by the light intensity, which was continuously monitored by the photoemission current from a gold-plated mesh inserted in the beam line. Our LPLS apparatus provides a pulse photon beam with the intensity of $10^{7}-10^{8}$ photon/pulse, the pulse width less than 15 ns. The wavelength resolution $\lambda / \Delta \lambda$ is $50-100$. The characteristics of our light source make it possible to obtain higher time resolution in a TOF measurement of desorbed particles in comparison with our previous PSD study using synchrotron radiation as a light source [20]. The copper substrate is thermally connected and electrically insulated by a sapphire rod to a liquid He reservoir. The sample temperature was $5.9 \mathrm{~K}$. A positive bias was applied to the sample to accelerate cations, which were extracted into the field free region of the drift tube and detected by a channeltron electron multiplier.

The ESD chamber was equipped with a pulsed electron gun, a copper substrate, gas doser systems and a TOF spectrometer. The electron beam was pulsed at $1.8 \mathrm{kHz}$ with a pulse width of $\sim 30 \mathrm{~ns}$. To minimize sample charging in ESD experiment, the average current of the pulsed-beam was suppressed below $\sim 0.3 \mathrm{nA}$. Water was physisorbed on the rare gas solid that were condensed on an insulated copper substrate attached to a He gas flow cryostat. The temperature of the substrate was controlled in the range between $8.7 \mathrm{~K}$ and $45 \mathrm{~K}$ by adjusting the flow rate of cold He gas by an automatic piezo valve.

\section{Time-of-flight spectrum}

The PSD-TOF spectrum of the positive ions from $\mathrm{H}_{2} \mathrm{O}$ (0.4 ML) physisorbed on solid $\mathrm{Ne}(300 \mathrm{ML})$ at $5.9 \mathrm{~K}$ is shown in Fig. 1, $a$. The incident photon energy was $70 \mathrm{eV}$. A series of protonated water cluster ions, $\left(\mathrm{H}_{2} \mathrm{O}\right)_{n} \mathrm{H}^{+}(n=1-37)$, are desorbed together with relatively weak signals of $\mathrm{H}^{+}, \mathrm{Ne}^{+}, \mathrm{Ne}_{2}^{+}$, and unprotonated clusters, $\left(\mathrm{H}_{2} \mathrm{O}\right)^{+}{ }_{n}(n=1-3)$. The $\left(\mathrm{H}_{2} \mathrm{O}\right){ }_{n} \mathrm{H}^{+}$ desorption is observed from a submonolayer film of water adsorbed on solid $\mathrm{Ar}, \mathrm{Kr}$ and $\mathrm{Xe}$. From water (0.4 ML) adsorbed on a bare copper substrate, on the contrary, there are no detectable PSD ions except $\mathrm{H}^{+}$ (Fig. 1,b). These results indicate that the rare gas substrates have a close connection with the enhancement 


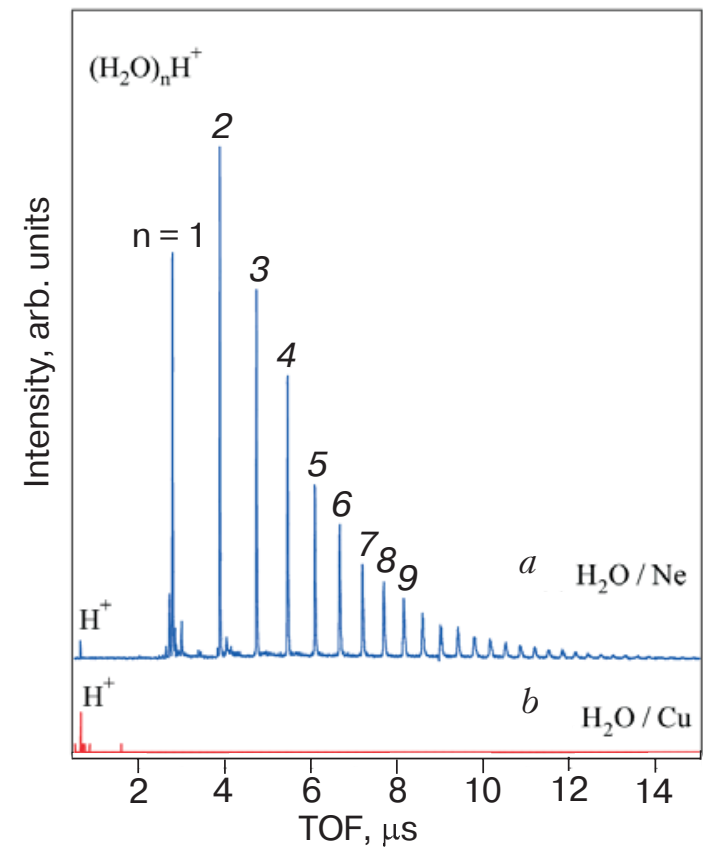

Fig. 1. TOF spectra of PSD ions from $(a)$ water $(0.4$ ML) physisorbed on Ne films (100 ML), and (b) on the copper substrate. The incident photon energy is $70 \mathrm{eV}$. The sample temperature is $5.9 \mathrm{~K}$.

of the $\left(\mathrm{H}_{2} \mathrm{O}\right)_{n} \mathrm{H}^{+}$desorption. From the ice multilayer, ESD of $\left(\mathrm{H}_{2} \mathrm{O}\right)_{n} \mathrm{H}^{+}(n=1-8)$ was also observed by Orlando and his coworkers $[8,9]$, which is due to a Coulomb repulsion between two adjacent ionic water molecules. However, the yield of cluster ions is much lower than the yield of $\mathrm{H}^{+}$, and the size $n$ distribution of desorbed clusters from condensed ice is not similar to that in Fig. 1,a. It is suggested that the desorption mechanism of cluster ions on the rare gas solid differs from that on the ice multilayer. In our previous PSD experiments [19], measurement of the $\left(\mathrm{H}_{2} \mathrm{O}\right)_{n} \mathrm{H}^{+}$ desorption yield as a function of the incident photon energy indicated that the multiple-excitation and -ionization of rare gas substrates effectively induce the $\left(\mathrm{H}_{2} \mathrm{O}\right)_{n} \mathrm{H}^{+}$desorption, while the direct excitation of the water molecule did not induce the noticeable desorption of clusters. On the basis of this observation, we have proposed that the $\left(\mathrm{H}_{2} \mathrm{O}\right)_{n} \mathrm{H}^{+}$desorption is due to Coulomb repulsion between the rare gas ion and the protonated water cluster, which are produced by charge transfer process between the multiple-charged rare gas ion and ground state water cluster [19]. This can be written as

$$
\begin{aligned}
\mathrm{R}+h v \rightarrow \mathrm{R}^{++}+2 e \\
\mathrm{R}^{++}+\left(\mathrm{H}_{2} \mathrm{O}\right)_{m} \rightarrow \mathrm{R}^{+}+\left[\left(\mathrm{H}_{2} \mathrm{O}\right)_{m}{ }^{+}\right]^{*}, \\
\mathrm{R}^{+}+\left[\left(\mathrm{H}_{2} \mathrm{O}\right)_{m}{ }^{+}\right]^{*} \rightarrow \mathrm{R}^{+}+\left(\mathrm{H}_{2} \mathrm{O}\right)_{k} \mathrm{H}^{+}+\mathrm{OH}+ \\
+(m-k-1) \mathrm{H}_{2} \mathrm{O},
\end{aligned}
$$

where $\mathrm{R}$ represents a rare gas atom, and an asterisk (*) denotes an electronic excited states. The protonated water cluster are created on the rare gas solid as the result of the dissipation of the excess energy in an excited water molecule [21]. Coulomb repulsion between the adjacent ion pair, $\left(\mathrm{H}_{2} \mathrm{O}\right){ }_{n} \mathrm{H}^{+}$and $\mathrm{R}^{+}$, yields the kinetic energy of desorbing cluster ion.

\section{Water coverage dependence}

The yields of $\mathrm{H}^{+}$and $\left(\mathrm{H}_{2} \mathrm{O}\right)_{n} \mathrm{H}^{+}(n=1-10)$ as a function of water coverage using $500 \mathrm{eV}$ electron are shown in Fig. 2. The sample temperature is $20 \mathrm{~K}$. The yield of each clusters $(n=1-10)$ shows a maximum at $0.1-0.3$ monolayer of water coverage and decreases significantly with increasing the coverage. Physisorbed water molecules on the rare gas solid form clusters at the submonolayer coverage regime due to its strong hydrogen bonding interactions with adjacent water molecules, and these clusters coalesce into larger islands at higher coverage. Therefore, the behaviors shown in Fig. 2 can be interpreted that the desorbed $\left(\mathrm{H}_{2} \mathrm{O}\right)_{n} \mathrm{H}^{+}$ions are originated from the isolated water clusters on the rare gas surface. When the adsorbed clusters grow up to a large size island or bulk ice, the cluster ions are hardly desorbed from them. The coverage dependence of the $\left(\mathrm{H}_{2} \mathrm{O}\right)_{n} \mathrm{H}^{+}$yield is much different from that of the proton yield. The $\mathrm{H}^{+}$yield reaches to a near saturation value at $\sim 2 \mathrm{ML}$. The difference between the cluster ions and the proton in the depend-

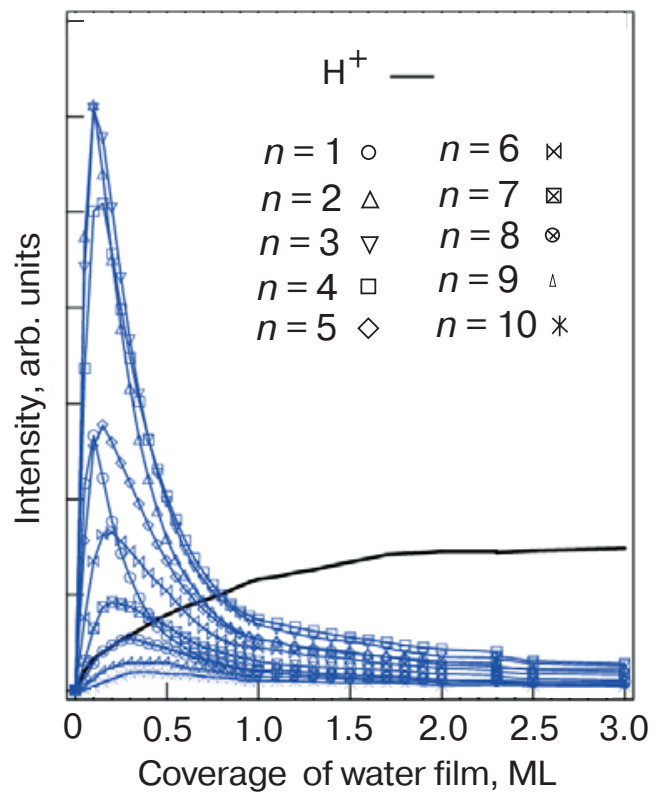

Fig. 2. Desorption yields of $\mathrm{H}^{+}$and $\left(\mathrm{H}_{2} \mathrm{O}\right)_{n} \mathrm{H}^{+}(n=$ =1-10) from water physisorbed on Xe films (300 ML) as a function of water coverage. The incident electron energy is $500 \mathrm{eV}$. The sample temperature is $20 \mathrm{~K}$. 


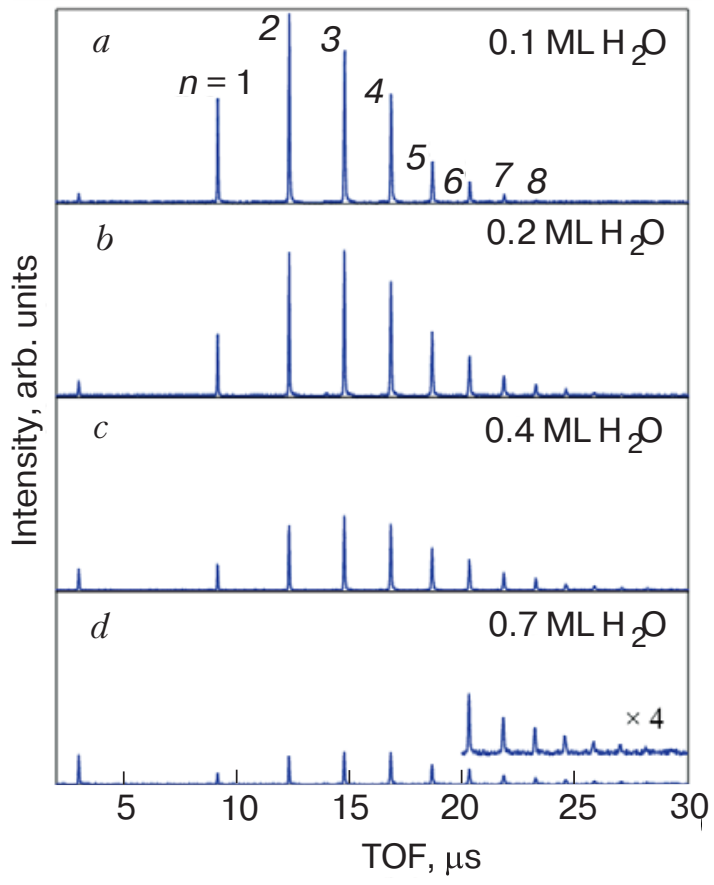

Fig. 3. TOF spectra of ESD ions from water physisorbed on solid $\mathrm{Xe}(300 \mathrm{ML})$ as a function of $\mathrm{H}_{2} \mathrm{O}$ coverage. The incident electron energy is $500 \mathrm{eV}$. The sample temperature is $20 \mathrm{~K}$.

ence on the water thickness should be attributed to different desorption mechanism.

ESD-TOF spectra from $\mathrm{H}_{2} \mathrm{O}$ films on solid Xe (300 ML) of various water coverages using $500 \mathrm{eV}$ electron at $20 \mathrm{~K}$ are shown in Fig. 3. It is found that the TOF distribution strongly depends on the water coverage. The size distribution of desorbed cluster ions shifts toward the larger $n$ with increasing coverage. This result indicated that the size shift of desorbed $\left(\mathrm{H}_{2} \mathrm{O}\right)_{n} \mathrm{H}^{+}$is due to change in the adsorbed cluster distribution and cluster density as the coverage increases.

\section{Temperature dependence}

ESD-TOF spectra from $\mathrm{H}_{2} \mathrm{O}(0.1 \mathrm{ML})$ adsorbed on solid Xe (300 ML) at the various deposition temperatures of water are shown in Fig. 4. The incident electron energy is $500 \mathrm{eV}$. The size distribution of desorbed cluster ions shifts toward the larger $n$ as the deposition temperature is increased. On the metal substrates, the diffusion and aggregation behaviors of the single water molecules have been reported by several groups [22-24], and it is well known that the thermally activated diffusion have a strong influence on the structure and size distribution of the clusters on the surface at even low substrate temperatures, for instance, such as on $\mathrm{Cu}(111)$ below $16 \mathrm{~K}$ [24]. From this viewpoint, the temperature dependence of desorbed cluster ions is un-

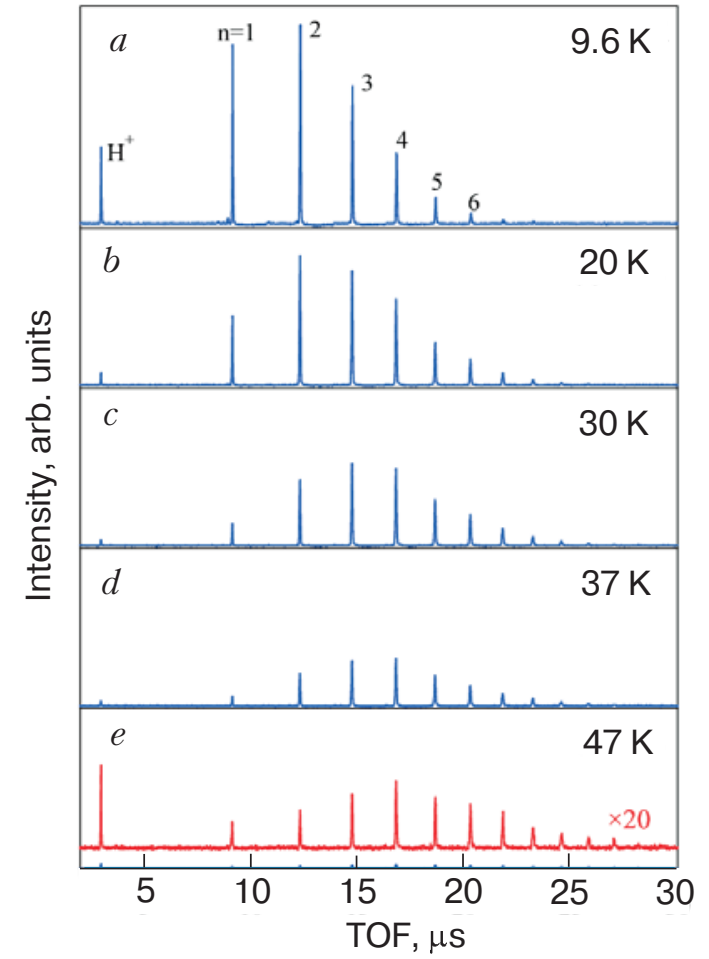

Fig. 4. ESD-TOF of ESD ions spectra from water (0.1 ML) physisorbed on solid Xe (300 ML) at the different temperatures of deposition.

derstood the surface diffusion of $\mathrm{H}_{2} \mathrm{O}$ molecules and small clusters on the rare gas solid. It is likely that smaller clusters can migrate on the surface and formed

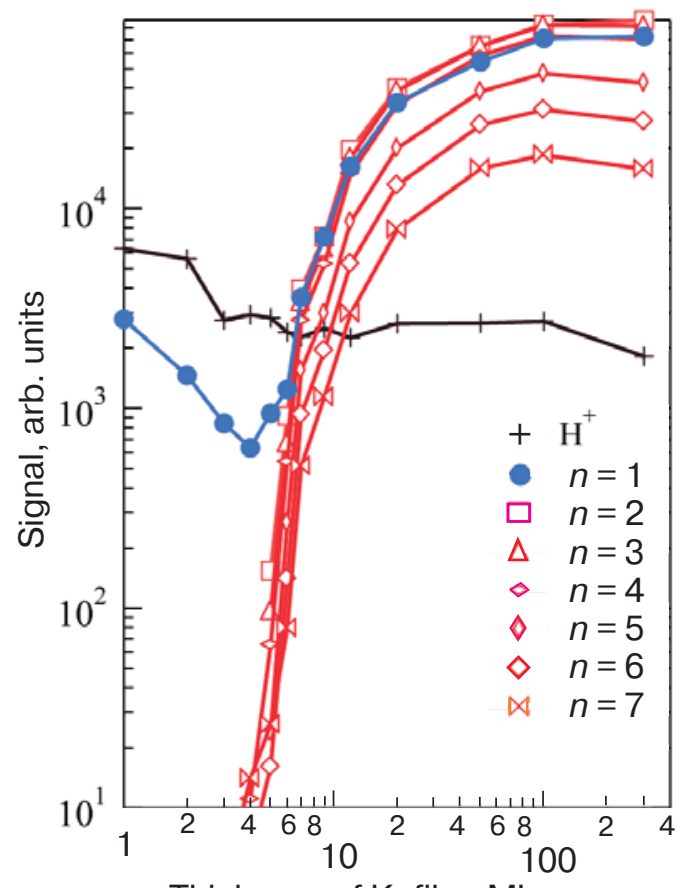

Thickness of $\mathrm{Kr}$ film, ML

Fig. 5. Desorption yield of $\left(\mathrm{H}_{2} \mathrm{O}\right)_{n} \mathrm{H}^{+}(n=1-10)$ as a function of thickness of $\mathrm{Kr}$ films. The incident electron energy is $500 \mathrm{eV}$. The sample temperature is $20 \mathrm{~K}$. 
the lager clusters and islands as the deposition temperature increases. Consequently, the growth of clusters by the surface diffusion process is reflected in the size distribution of $\left(\mathrm{H}_{2} \mathrm{O}\right)_{n} \mathrm{H}^{+}$.

\section{Rare gas thickness dependence}

The yields of $\mathrm{H}^{+}$and $\left(\mathrm{H}_{2} \mathrm{O}\right)_{n} \mathrm{H}^{+}$as a function of the thickness of $\mathrm{Kr}$ films are shown in Fig. 5. At a thickness of the rare gas films less than $\sim 4 \mathrm{ML}$, only $\mathrm{H}^{+}$and $\mathrm{H}_{3} \mathrm{O}^{+}$are desorbed, which are gradually decreased with increasing rare gas thickness. These ions are also observed from water directly adsorbed on the bear copper substrate. The results indicate that these ions are desorbed from water molecules adsorbed on the copper surface and the growth of $\mathrm{Kr}$ films on the surface impedes the ion desorption from them. At $\sim 4 \mathrm{ML}$ of rare gas films on the copper substrate, the

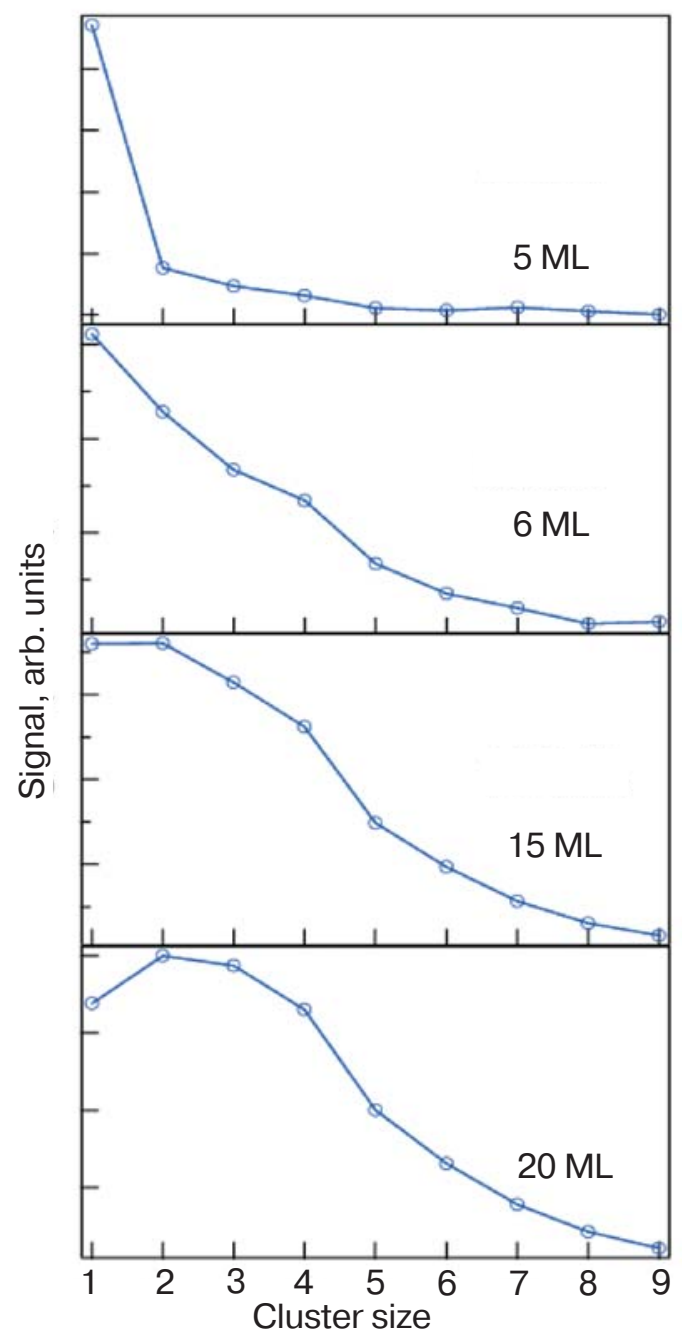

Fig. 6. Protonated water cluster yield from water (0.1 ML) physisorbed on the $\mathrm{Kr}$ films as a function of the number of water molecules in the cluster. The incident electron energy is $500 \mathrm{eV}$. The sample temperature is $20 \mathrm{~K}$. signals of the cluster ions $(n \geq 2)$ appear in TOF measurements, and the $\mathrm{H}_{3} \mathrm{O}^{+}$yield changes to an increase. These yields rise dramatically with increasing thickness and reach to a near saturation value at $\geq 40 \mathrm{ML}$. The behaviors of the yields versus the rare gas film thickness $(\geq 4 \mathrm{ML})$ is apparently identical for $\mathrm{H}_{3} \mathrm{O}^{+}$ and $\left(\mathrm{H}_{2} \mathrm{O}\right)_{n} \mathrm{H}^{+}(n=2-10)$, suggesting that they are produced by the same desorption process on the rare gas films thicker than $4 \mathrm{ML}$. The result shows that the desorption of the water cluster ions $(n \geq 2)$ occurs from the water clusters adsorbed on the rare gas films. The saturation of the yields is observed at rather thick films ( $40 \mathrm{ML})$ of the rare gas solid. The thickness dependence would reflect the reduction of quenching of the transient excited states in the rare gas solid as the distance to the metal interface is increased.

The size $n$ distribution of $\left(\mathrm{H}_{2} \mathrm{O}\right)_{n} \mathrm{H}^{+}$for various thickness of the $\mathrm{Kr}$ film is shown in Fig. 6. From the thin rare gas films, the large size clusters cannot be observed. This result indicated that the thickness and the morphology of rare gas film on the copper surface influence the growth of the clusters.

\section{Kinetic energy distribution}

TOF measurements were also applied to determine the velocity distribution of the PSD ions. The velocity distribution taken under the field free conditions, the bottom curve in Fig. 7, is converted into a kinetic energy distribution by using the Jacobian transformation [9], which is shown in Fig. 8. The kinetic energy of the water cluster ions strongly depend on the rare gas species of the substrates. The energy distribution was

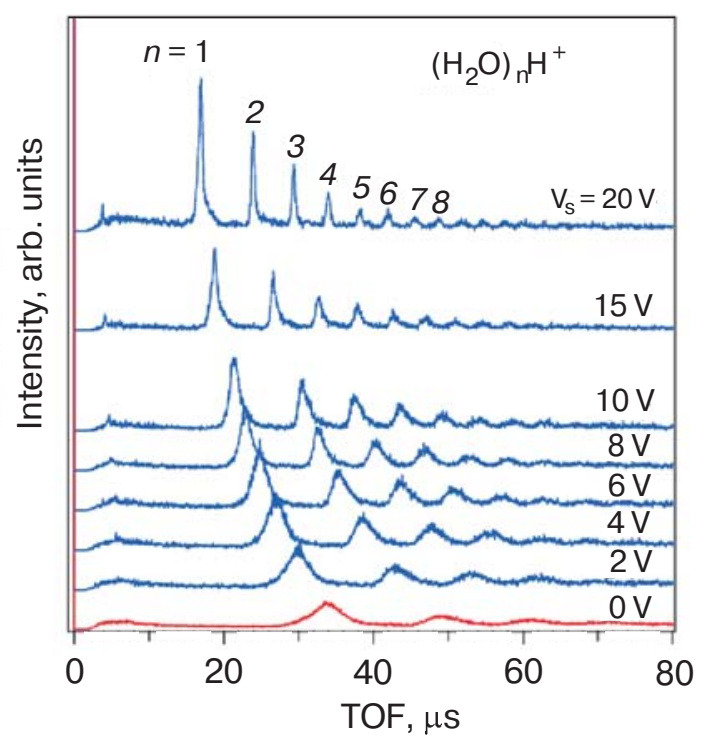

Fig. 7. Velocity distributions of $\left(\mathrm{H}_{2} \mathrm{O}\right)_{n} \mathrm{H}^{+}$from water (0.1 ML) physisorbed on Ne films (300 ML) as a function of bias voltage $V_{S}$ applied to substrate. The incident photon energy is $93.5 \mathrm{eV}$. The sample temperature is $5.9 \mathrm{~K}$. 


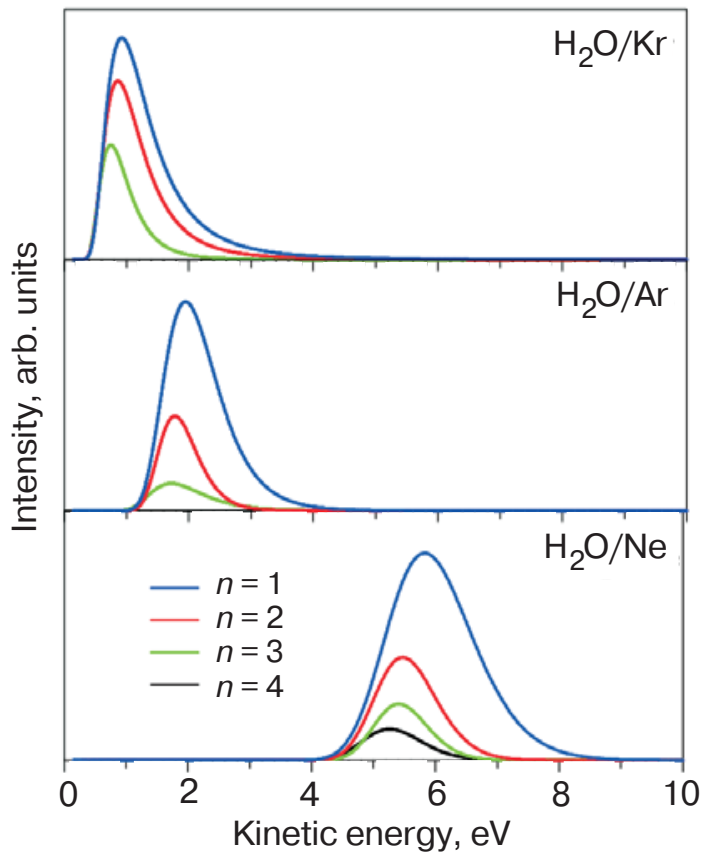

Fig. 8. $\left(\mathrm{H}_{2} \mathrm{O}\right)_{n} \mathrm{H}^{+}$kinetic energy distributions from water (0.1 ML) physisorbed on $\mathrm{Kr}$, Ar, and $\mathrm{Ne}$ films, respectively. The incident photon energy is $93.5 \mathrm{eV}$. The sample temperature is $5.9 \mathrm{~K}$. Measurements were made under a field free condition.

also analyzed by using a cylindrical mirror analyzer (not shown) and the same behavior was confirmed.

It has been thought that the driving force for the desorption of ions is Coulomb repulsion between adjacent ion pair or two holes in a molecule [9,11]. Obvious difference of the kinetic energy of the water cluster ions for the different substrates suggests that the Coulomb repulsion between two holes in a water cluster is not the case for our observation. They are ejected by that between an ionized water cluster and a rare gas ion in the substrate. This result supports our desorption model [19]. The dominant factor which will cause the difference in the kinetic energy of desorbed species must be an initial inter-ion distance, which depends on the size of a rare gas molecule and that of a water cluster and on the position of the hole in the cluster ion, the center of gravity of charge in other word. The binding energy between the rare gas surface and the water cluster should be another important factor for the difference in the kinetic energy. Observed value of the kinetic energies and these dependence on the rare gas species and the cluster size would be reasonable as far as in qualitative manner. Quantitative evaluations of these values which are not shown here, however, are not satisfactory in the present state.

\section{Summary}

The desorption of the protonated water cluster, $\left(\mathrm{H}_{2} \mathrm{O}\right)_{n} \mathrm{H}^{+}$, from water physisorbed on the rare gas solids has been investigated. The size distribution of $\left(\mathrm{H}_{2} \mathrm{O}\right)_{n} \mathrm{H}^{+}$shifts toward the larger $n$ with increasing coverage and increasing deposition temperature of water. The $\left(\mathrm{H}_{2} \mathrm{O}\right)_{n} \mathrm{H}^{+}$yields show a maximum at $0.1-0.3$ monolayer of water coverage and decreased significantly with increasing the coverage. A rare gas film as thin as 4-6 ML on the copper substrate leads the desorption of $\left(\mathrm{H}_{2} \mathrm{O}\right)_{n} \mathrm{H}^{+}$which yield increased noticeably with the thickness of the rare gas film. It is found that the $\left(\mathrm{H}_{2} \mathrm{O}\right)_{n} \mathrm{H}^{+}$ions are originated from the isolated water clusters on rare gas solid and the size shift of desorbed cluster ions relevant to the growth of water clusters. The measurement of kinetic energy distributions indicated that the desorbing energy of clusters depend on the rare gas species of the substrates and the cluster size. It is suggested that the $\left(\mathrm{H}_{2} \mathrm{O}\right)_{n} \mathrm{H}^{+}$are ejected by the Coulomb repulsion between the protonated water cluster and the rare gas ion in the substrate.

1. Q.B. Lu and L. Sanche, Phys. Rev. Lett. 87, 078501 (2001).

2. M.T. Siger, W.C. Simpson, and T.M. Orlando, $N a^{-}$ ture 394, 554 (1998).

3. R. Bianco and J.T. Hynes, J. Phys. Chem. A102, 309 (1998).

4. G.M. Muňoz Caro, U.J. Meierhenrich, W.A. Schutte, B. Barbier, A. Arcones Segovia, H. Rosenbauer, W.H.P. Thiemann, A. Brack, and J.M. Greenberg, Nature (London) 416, 403 (2002).

5. J.O. Noell, C.F. Melius, and R.H. Stulen, Surf. Sci. 157, 119 (1985).

6. T.M. Orlando, A.B. Aleksandrov, and J. Herring, Surf. Sci. 107, 9370 (2003).

7. M.T. Siger, W.C. Simpsom, and T.M. Orlando, Phys. Rev. B56, 4925 (1997).

8. J. Herring, A. Aleksandrov, and T.M. Orlando, Phys. Rev. Lett. 92, 1876021 (2004).

9. J.H. Captain, G.A. Grieves, A. Alexandrov, M.T. Sieger, H. Chen, and T.M. Orlando, Phys. Rev. B72, 035431 (2005).

10. R. Baggott, K.W. Kolasinski, L.M.A. Perdig'ao, D. Riedel, Q. Guo, and R.E. Palmer, J. Chem. Phys. 117, 6667 (2002).

11. R. Souda, J. Chem. Phys. 117, 5967 (2002).

12. W.C. Simpson, T.M. Orlando, L. Parenteau, K. Nagesha, and L. Sanche, J. Chem. Phys. 108, 5027 (1998).

13. G.A. Kimmel and T.M. Orlando, Phys. Rev. Lett. 77, 3983 (1996).

14. R. Rowntree, L. Parenteau, and L. Sanche, J. Chem. Phys. 94, 8570 (1991). 
15. W.C. Simpson, L. Parenteau, R.S. Smith, L. Sanche, and T.M. Orlando, Surf. Sci. 390, 86 (1997).

16. G.A. Kimmel and T.M. Orlando, Phys. Rev. Lett. 75, 2606 (1995).

17. T.M. Orlando and G.A. Kimmel, Surf. Sci. 390, 79 (1997).

18. M. Sakurai, T. Hirayama, and I. Arakawa, Vacuum 41, 217 (1990).

19. T. Tachibana, Y. Yamauchi, T. Miura, T. Hirayama, M. Sakurai, and I. Arakawa, Surf. Sci. 593, 264 (2005).
20. T. Hirayama, A. Hayama, T. Adachi, I. Arakawa, and M. Sakurai, Phys. Rev. B63, 075407 (2001).

21. H. Shinohara, N. Nishi, and N. Washida, J. Phys. Chem. 84, 5561 (1986).

22. S. Andersson, C. Nyberg, and C.G. Tengstal, Chem. Phys. Lett. 104, 189 (1994).

23. T. Mitsui, M.K. Rose, E. Fomin, D.F. Ogletree, and M. Salmeron, Science 297, 1850 (2002).

24. K. Morgenstern and K. Rieder, J. Chem. Phys. 116, 5746 (2002). 